\title{
TI.70.1
}

\section{Concerns in the use of Endpoint Agent Security Tools}

- PDF: 20081014-endpoint-kassabian.pdf

- Text: 20081014-endpoint-kassabian.txt

\section{More Information}

\begin{tabular}{|c|c|}
\hline Repository ID & TI.70.1 \\
\hline Persistent URL & http://doi.org/10.26869/TI.70.1 \\
\hline Title & Concerns in the use of Endpoint Agent Security Tools \\
\hline Authors & Deke Kassabian \\
\hline Sponsor & SALSA \\
\hline \multicolumn{2}{|l|}{ Review } \\
\hline Status & Legacy \\
\hline Publish Date & October 14, 2008 \\
\hline DOI & $10.26869 / \mathrm{TI} .70 .1$ \\
\hline \multicolumn{2}{|l|}{ Signature } \\
\hline Deprecated & No \\
\hline \multicolumn{2}{|l|}{ Future Review } \\
\hline \multicolumn{2}{|l|}{ Supersedes } \\
\hline Format & PDF, Text \\
\hline \multicolumn{2}{|l|}{ Related Docs } \\
\hline \multicolumn{2}{|l|}{ Development Location } \\
\hline \multicolumn{2}{|l|}{ IP Framework } \\
\hline Subject Tags & middlewarerescue \\
\hline Notes & \\
\hline
\end{tabular}

